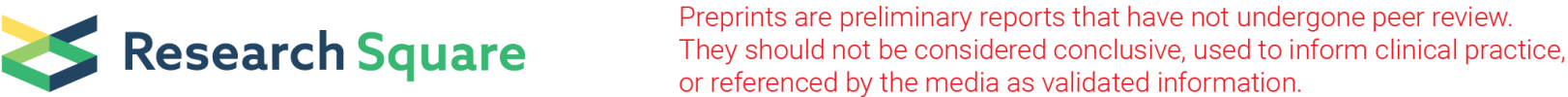

\section{The relationship between empathy and altruistic motivations in nursing studies: A multi-method study}

Linda Messineo ( $\square$ linda.messineo@itd.cnr.it)

Istituto per le Tecnologie Didattiche Consiglio Nazionale delle Ricerche https://orcid.org/0000-00029486-5368

\section{Luciano Seta}

Istituto per le Tecnologie Didattiche Consiglio Nazionale delle Ricerche Unita Operativa di Palermo

\section{Mario Allegra}

Istituto per le Tecnologie Didattiche Consiglio Nazionale delle Ricerche Unita Operativa di Palermo

\section{Research article}

Keywords: Degree choice, Empathy, Jefferson Scale of Empathy - Health Professions Students Version, Thematic analysis, Undergraduate students

Posted Date: November 4th, 2020

DOI: https://doi.org/10.21203/rs.3.rs-59634/v2

License: (c) (1) This work is licensed under a Creative Commons Attribution 4.0 International License. Read Full License

Version of Record: A version of this preprint was published at BMC Nursing on July 7th, 2021. See the published version at https://doi.org/10.1186/s12912-021-00620-4. 


\section{Abstract}

Background. The efficient management of relational competences in healthcare professionals is crucial to ensure that a patient's treatment and care process is conducted positively. Empathy is a major component of the relational skills expected of health professionals. Knowledge of undergraduate healthcare students' empathic abilities is important for educators in designing specific and efficient educational programmes aimed at supporting or enhancing students' empathic competences. In this study, we measured first-year undergraduate nursing students' attitudes towards professional empathy in clinical encounters. The students' motivations for entering nursing education were also evaluated. This study takes a multi-method approach based on the use of qualitative and quantitative tools to examine the association between students' positive attitudes towards the value of empathy in health professionals and their prosocial and altruistic motivations in choosing to engage in nursing studies.

Methods. A multi-method study was performed with 77 first-year nursing students. The Jefferson Scale of Empathy (JSE) - Health Professions Student Version was administered. Students' motivations for choosing nursing studies were detected through an open question and thematically analysed. Using explorative and confirmative factor analyses, a dimension reduction was conducted to identify subjects with prosocial and altruistic motivations. Finally, linear models were tested to examine specific associations between motivation and empathy.

Results. Seven distinct themes distinguishing internal and external motivational factors were identified through the thematic analysis of students' answers regarding their choice of entering the nursing degree course. Female students gained higher scores on the empathy scale than their male counterparts. When students' age was considered, this difference was shown only for younger students, with young females' total scores being higher than those of young males. High empathy scores were positively associated with altruistic motivational factors. A negative correlation was found between external motivational factors and the scores of the Compassionate Care subscale of the JSE.

Conclusions. Knowing the level of nursing students' empathy and their motivational factors for entering nursing studies is important for educators in order to implement training paths that enhance students' relational attitudes and skills and promote positive motivational aspects that are central to this profession.

\section{Background}

In recent decades, there has been a growing amount of empirical scientific research on the importance of positive relationships between health professionals and patients to ensure the improvement of the cure and treatment process [1]. Health specialists need to master interpersonal and communication skills, including the willingness to listen, grasping what patients communicate with interest, and being aware of patients' attitudes and psychological characteristics [2]. Several studies have attempted to determine whether interactions between clinicians and patients have a beneficial effect on health-related outcomes. 
Kelley et al. [1] conducted a systematic review and meta-analysis of research in which this specific relationship was examined. They suggested that the clinician-patient relationship has a small but statistically significant effect on healthcare outcomes such as blood pressure or pain scores. Healthcare professionals with good interpersonal skills and empathy towards patients have a positive and significant impact on patient satisfaction and adherence to treatment $[3,4,5]$, the outcomes of care [6], and a higher agreement on decisions made in clinical consultations [7]. Empathy is a meaningful factor in the healthcare professional-patient relationship $[1,8]$. Moreover, empathy is one of the most powerful personal attributes that health professionals can use to encourage patients to modify their health, producing positive clinical outcomes [9]. Patients should perceive health professionals as empathic people. Empathy allows patients to feel understood, validated, and respected [10]. Several studies have identified empathy as a useful skill for nurses regarding its impact on the improvement of patient outcomes such as distress and anxiety [11]. Much attention has been dedicated to this issue, and the importance of healthcare personnel taking an empathic approach has been stressed [12]. Further, many educational programmes have focused on promoting empathy in undergraduate students and healthcare professionals $[13,14,15,16]$. However, debates among researchers regarding the description and operationalisation of empathy are still open, with the related considerations about specific instruments for empathy measurement in the health sector, in general, and in nursing, in particular $[12,17,18,19,20]$. Empathy does not have a clear and unambiguous definition [17]; it is a multi-dimensional construct characterised by cognitive and affective aspects [12]. Cognitive empathy refers to the ability by which health professionals understand patients' experiences and emotions and have the competence to communicate this understanding to patients. Emotional empathy is related to the emotional responses of participation and sharing of healthcare personnel to the patients' feelings. In a caring relationship, such as the nurse-patient relationship, empathy is principally characterised by the cognitive component [12]. This competence is developed over the course of one's life; all individuals are typically found to have intermediate levels of this ability, though they fall at different locations on the empathy spectrum. Research has shown that health profession students' empathy declines over the course of their training $[21,22,23]$. Conversely, some recent studies have reported no change or an increase of empathy during undergraduate education $[24,25,26]$. Promoting empathy is one of the objectives of healthcare education $[13,14,15,16,27]$. It is important for educators to understand undergraduate healthcare students' empathy levels in order to tailor educational programmes to support or enhance students' empathic competences. Various instruments have been created to measure empathy levels in healthcare-related contexts $[17,18,20]$. One of the most commonly used surveys to measure empathy in the healthcare sector is the Jefferson Scale of Empathy (JSE) [28]. Different versions of the JSE have been developed for physicians and other health professionals (HP version), for medical students (S version), and for students of other healthcare specialties (HPS version) [12], the last of which has been used in this study.

Prior research has focused on the association between medical students' empathy and their motivation for studying, an important factor which may influence academic achievement and student retention [29]. A weak association between empathy and reasons for enrolling in medical courses has been observed by some researchers [30]. Another study showed a significant association between the empathy scores of 
first-year medical students and their intention to pursue people-oriented specialties after graduation [31]. A recent study showed a significant positive association between internal motivational factors (such as altruism or caring for patients) for studying medicine and empathy [32]. Another study concluded that there is no association between the JSE scores and speciality interest in osteopathic medical students [33]. No studies have investigated the association between students' positive attitudes towards the value of empathy in health professionals and their motivation for engaging in nursing studies. Students' motivations and reasons for choosing to take a nursing university course and follow nursing as a career have been explored in different studies. Such research has found that these choices are the result of a combination of internal and external motivational factors; sometimes, nursing is not students' first options. Students choose to engage in the nursing profession based on their desire to help other people and engage in activities and perform work with social benefits [34, 35, 36, 37, 38, 39, 40]. External motivational factors such as career opportunities and job security, are also important in students' career choices $[34,38,39]$. Personal health-related experiences such as hospitalisation, the illness of a family member, or a volunteering experience, have been detected as additional motivations [34, 36, 37]. Furthermore, some students choose nursing studies due to their interest in science subjects. Personal experiences and family members and friends can play key roles as main sources of information for nursing students concerning the nursing profession [41, 42]. Internal motivational factors for entering nursing, such as helping others, are the motivational factors most commonly indicated by students.

In the present study, we measured empathy of first-year undergraduate nursing students and their motivations to pursue nursing education. We expected to find an association between students' positive attitudes towards the value of empathy in health professionals and their altruistic motivations for choosing nursing studies. Altruistic motivations refer to the desire to perform voluntary actions in order to generate a benefit for others, promote well-being, and alleviate others' needs [43].

\section{Research hypotheses}

The primary aim of this study is to describe the association between empathy and reasons for enrolling in nursing. We expected to find a significant association between empathy scores and altruistic motivations for choosing nursing studies.

The secondary aims of this study are to verify whether there are significant age and gender differences in empathy scores and nursing motivations. According to the existing literature, we expected to find significant gender differences in empathy scores $[44,45,46,47]$. We also expected to identify age and gender differences with respect to nursing motivations [40].

\section{Methods}

\section{Study design}

Considering the explorative nature of this study, which was aimed at determining the existence of a relationship between empathy and motivation, a multi-method research approach was adopted. A 
quantitative tool was used to measure empathy, whereas for nursing motivation, replies to an open question were thematically analysed.

\section{Setting and data collection}

All students $(N=120)$ enrolled in the first year of the nursing degree course at the Medical School of a university in southern Italy were invited to participate in the study. According to the local ethical policy, no formal approval by the ethics committee was necessary. We communicated the study design to the institutional board of the degree course, guaranteeing that ethical standards would be met, and received consent. At the beginning of the first academic semester, data were collected in classroom settings. Students were informed about the aim of the research and the study procedure after class by one of the researchers (LM), a general psychology aggregate professor in the nursing degree course. Data collection was conducted only after obtaining informed consent from students attending LM's lectures. The confidentiality of the collected data was guaranteed, and the professor was unable to correspond the students with their responses. Participation was voluntary, and students could decide to withdraw their participation at any moment without any consequence. Data were collected by filling in a questionnaire structured for the purposes of the present study.

\section{Instruments and measures}

The students completed a three-part questionnaire to measure socio-demographic factors, their motivation for choosing nursing studies, and their empathy levels.

Socio-demographic factors. Through a few questions, some socio-demographic aspects were collected, such as age and gender.

Motivation for choosing nursing studies. An open question was administered to students to gather information regarding their motivations for choosing to enrol in a university nursing course. Students were asked to answer the following question: Describe your motivations for choosing a degree course in nursing. This open question stimulated students to think independently instead of choosing from predetermined responses in a structured questionnaire. Attitude towards empathy. Permission to use the Italian adaptation of the Health Professions Students version of the JSE (JSE-HPS) was obtained to measure students orientation towards the value of empathy in health professionals in clinical contexts $[12,48]$. The JSE-HPS is a self-report instrument and includes 20 items answered on a 7-point Likert scale ( 1 = strongly disagree, to 7 = strongly agree). The questionnaire comprises three factors: a) perspective taking, b) compassionate care/emotional engagement, and c) standing in the patient's shoes. The survey has been developed based on a robust research literature review regarding empathy activated in a relationship aimed to treat and cure a patient, in which health professionals acquire cognitive comprehension about patients' concerns and their general vision of health and illness and their abilities to communicate this understanding to their patients. A higher score on the JSE-HPS scale (the score range is 20 to 140) reflects a greater attitude towards empathic involvement in patient treatment. Studies have showed that females generally have significantly higher JSE scores than males $[44,45,46,47]$. 


\section{Qualitative data analysis}

The students' answers to the open question were analysed using thematic analysis to investigate their motivations for engaging in nursing studies [49]. Two independent evaluators (LM and LS) followed six phases to categorise the students' responses. During each phase of the thematic analysis, specific activities were performed to establish trustworthiness [50]. In the first phase, the two researchers read and familiarised themselves with the qualitative data, which consisted of 77 responses. They stored the data in well-organised archives and considered potential themes. After an in-depth reading of the responses, during the second phase, the two researchers independently conducted an analytic segmentation of the contents, with the aim of generating initial codes and recognising themes. The credibility of thematic analysis was enhanced by engaging two evaluators in the analysis of the qualitative data. Periodic meetings were held throughout the coding procedure for peer debriefing. During phase three, the researchers identified different analytical units in each section of the texts, such as words, phrases, statements or entire paragraphs, using similar words or expressing the same ideas, from which to extract meaningful core themes. They kept detailed notes about the development of themes. This process of inferential analysis, performed independently by the two evaluators, was followed by a discussion aimed at selecting relevant categories. Afterwards, during phase four, a second examination of the students' answers was conducted to refine the correspondence between content and selected categories. During phase five, themes were revised and defined, with the description of a set of codes representing single words or short phrases that best described the motivations for the students' decisions. A meeting was held to discuss each of the revealed themes, and the few differences were resolved through discussion. The result was produced during phase six and consisted of the creation of a report describing the process of coding and analysis, with the inclusion of representative quotes for each theme and a set of codes representing single words or short phrases that best described the motivations for the students' decisions.

The principal biases in thematic analysis, and in the qualitative research in general, are related to the selection of the sample, the choice of the materials for analysis and the interpretation of the selected information. All these issues may represent threats to the validity and reliability of the findings [51]. The following precautions were taken to control some of these sources of bias in this study:

- the sample was selected at the start of the academic year, and freshman nursing students were sampled to avoid influences from the academic context;

- the questions and respondents' answers were presented and gathered in written form to avoid misinterpretation and obtrusive tools such as audio/video records;

- the interpretation of responses to the open question was carried out inductively and not using a priori categories, by two different researchers;

- the analysis was conducted following the principal theoretical approaches to the motivation;

- the findings of the thematic analysis were compared with the categories described in the relevant literature, often obtained using different methodologies. 
Naturally, the decision to use a qualitative approach may raise questions regarding the comparability and transferability of the results $[52,53]$. These issues must be carefully considered when the potential impacts of the study are evaluated.

\section{Quantitative data analysis}

Data were analyzed using R and Statistical Package for Social Sciences (SPSS). The quantitative approach was applied to analyse the results of the JSE-HPS. Simple non-parametric tests, Kruskal-Wallis and Mann-Whitney tests, were applied to examine the existence of gender or age differences in the scores of the sample population. Moreover, the frequency distribution of the occurrences of the motivational categories in the sample was analysed to detect possible significant differences regarding gender and age.

A person-centred analysis was conducted to better understand the structure of the motivations that emerged from the thematic analysis. The patterns of co-occurrence of the motivational categories were highlighted using the correlation matrix. Then, two reduction methods were used to aggregate these categories: hierarchical cluster analysis and principal component analysis (PCA). The good agreement between the results of these two different methods enforces the results of this study. Finally, linear models were tested to study specific associations between motivation and empathy.

The mixed methodology proposed in this study, in which the results of a qualitative analysis have been elaborated and associated with the scores of a quantitative tool, can offer a first proposal to reduce the gap between different research methods in nursing science. This can help the passage from the current 'preparadigmatic state' toward the adoption of more coherent and rigorous research methods [54].

\section{Results}

\section{Demographic characteristics}

Of the 120 first-year nursing students, 77 (64.17\%) completed all three parts of the questionnaire. Respondents' mean age was $21.53(S D=4.02)$. The sample comprised $37.7 \%$ males $(n=29 ; M=23, S D=$ $3.36)$ and $62.3 \%$ females $(n=48 ; M=20.48, S D=4.80)$.

\section{Motivation for nursing studies}

The thematic analysis of students' answers to the open question concerning their choice of nursing degree course identified seven distinct themes:

- Willingness to care for people (HEL)

- Human contact (HUM)

- Healthcare-related personal experiences (EXP)

- Personal interest in scientific topics (TOP) 
- Job opportunities (JOB)

- Family tradition (FAM)

- Other

On average, two categories were selected for each subject $(M=1.86, S D=0.94)$. Table 1 summarises the identified themes and subthemes of the thematic analysis, with a brief description of each. The category 'Other' was not included in the following analyses due to their scarcity and heterogeneity.

As shown in Table 2, the highest reported motivation was the willingness to care for and help others (HEL). The second most frequently stated motivation concerned job opportunities (JOB). The category related to social influences (FAM) rarely appeared in students' reported answers.

Hierarchical cluster analysis, conducted using the R function 'heatmap', where the heat scale corresponding to the correlation matrix values, and confirmed with SPSS software, suggested associations among different categories (see Figure 1). The desire to help others (HEL) in association with the family's influence (FAM) formed the first cluster of motivation. The second cluster was the association between healthcare-related experiences (EXP), such as voluntary work in healthcare settings or a family member's hospitalisation, with the desire to enter into contact with other people (HUM). These two clusters were separated by the cluster formed by job opportunities (JOB) and personal interest in scientific topics (TOP).

This preliminary result seems to suggest a more complex motivational structure with respect to a dichotomous separation between internal and external motivational factors [40]. The internal motivational factors (EXP, HUM, HEL and FAM) can be subdivided into two clusters. The first cluster groups motivations oriented towards the individual (EXP and HUM), while the second groups the other two categories, which are more related to a prosocial attitude (HEL and FAM). The external dimension appears to be represented by the JOB and TOP categories.

An exploratory factorial analysis (EFA) was conducted to better understand these clusters of motivations. The properties of the correlation matrix, related to the limited sample size and the relative sporadic occurrence of the various categories, only partially support the possibility to conduct the EFA with three components with eigenvalues larger than 1, explaining $63 \%$ of the total variance (KMO test < .50 , Bartlett test: $\left.c^{2}=23.67, d f=15 ; p<0.1\right)$. The very good compatibility between the outcomes of the PCA, with three factors and varimax rotation, and the previous hierarchical structure (Table 3 ) supports the validity of these findings.

The loads in Table 3 confirm the motivational structure in Figure 1. In particular, the second rotated component, denominated RC2 in Table 3, appears connected to an external dimension, with job opportunities as the strongest motivational theme. The third component, denominated RC3, seems to correspond to internal motivations oriented to individual interests, with major loadings on the categories EXP and HUM related to personal experience and human personal contact, respectively. Finally, the first 
RC1 component reflects the internal motivations with a prosocial orientation, and the categories HEL and FAM prevail; that is, categories oriented towards the needs of other people, with a negative correlation with TOP. Motivation and empathy scores are separately analysed in the subsequent part of this paper, after which correlations between motivation and the scores in the JSE questionnaire are examined.

Observing the frequencies of the different categories with respect to gender and age, some differences can be highlighted (see Table 2). In females' motivations, the categories that refer to the willingness to help and care, as well as healthcare related experiences, are recurrent (HEL, HUM, and EXP). In males, the highest reported motivations, other than the HEL category, are more oriented towards job security (JOB) and interest in scientific topics (TOP). This gender difference is statistically significant $\left(c^{2}=34.22, d f=5\right.$; $p<0.01)$.

For the younger students ('Young' and 'Mid' classes in Table 2, age $£ 21$ ), the frequencies of the motivation categories are not different with respect to the total sample. Older students ('Old' class in Table 2, age > 21) were shown to give more relevance to motivations related to job opportunities (JOB). These differences have a weaker statistical significance $(p<0.04)$.

\section{Empathy scores}

Descriptive statistics are reported in Table 4 regarding the JSE-HPS administered to the first-year students in the nursing degree course. The mean and standard deviation of the JSE-HPS empathy total scores and the statistical analysis are summarised. Considering the JSE scores reported in the literature $[28,48]$, the statistics that were obtained agree with the expected values and confirm a good external validity of the data collected in this sample.

Taking gender into account (Table 5), the mean of empathy scores was higher for female students $(M=$ $114.90, S D=10.20)$ than for males $(M=106.90, S D=12.97)$. The non-parametric Kruskal-Wallis test confirmed a significant difference $\left(c^{2}=6.73, d f=1 ; p<0.01\right)$ between the empathy total scores, and this difference was more significant if the subscale 'Compassionate Care' is considered $\left(c^{2}=11.16\right)$

Regarding age, there was no significant correlation between the JSE scores and students' age when tested with an ordinary linear regression model. The separate analysis of each of the three age classes ('Young', with age $£$ 19; 'Mid', with ages between 20 and 21; 'Old', with age > 21) confirms differences among the groups. The study of the interaction between age and gender shows a significant effect for the differences in the total JSE scores only in the case of younger students, with young females' total scores being higher than those of young males $(p<0.05)$. For the other two age classes, these differences were not statistically significant.

\section{Associations between the motivation for choosing nursing studies and JSE-HPS empathy scores}

The data in Table 5 show that higher empathy scores are associated with internal motivation, particularly with the internal motivations with a prosocial orientation (HEL and FAM). The external motivational 
factors (JOB and TOP) are associated at mean scores below the average, but this difference is only significant for the TOP category.

The results of the PCA were used to obtain a more statistically significant analysis of the associations between motivation and empathy scores.

Starting from the components illustrated in Table 3, it is possible to obtain a personal score vector for each student in the sample, which summarises their position in the three-dimensional space defined by the three rotated components: RC1, RC2, and RC3. Consequently, all components can be regressed on the JSE-HPS scores. When the JSE scores are used, we obtain two interesting correlations: a positive correlation between the prosocial scores (RC1) and the JSE total scores, and a negative correlation between the external dimension scores (RC2) and the scores in the JSE-HPS subscale 'Compassionate Care' (see Table 6). No other analysis shows statistically significant results.

\section{Discussion}

This study aimed to investigate the association between nursing students' positive attitudes towards the value of empathy and their altruistic motivations for choosing to engage in nursing studies. The motivations of 77 first-year students to engage in nursing studies were described, and their empathy was measured with a broadly used and valid instrument, the Health Professions Students' version of the JSE. We hypothesised a positive association between these two dimensions. We also hypothesised the association of nursing motivation and empathy scores with age and gender. First, the motivations to engage in nursing studies were examined through a thematic analysis. This analysis showed an interesting motivational structure, with the internal motivations appearing separate in two subdimensions. One sub-dimension was more related to individual interests, such as personal life experiences or interests in human contact. The other sub-dimension was more related to an altruistic stance, where an important role is played both by the desire to help other people and the family's influence. The external extreme of the motivational scale seems occupied by motivations related to job opportunities. A large proportion of students indicated altruistic motivations for choosing nursing studies, corresponding to the literature on this topic $[34,35,36,37,38,39,40]$. The analysis of gender differences indicated that internal motivations were more present in the female students' responses to the open question as opposed to their male counterparts, whose responses more oriented towards external motivations. Furthermore, female students reported a higher mean score on the JSE; these results are consistent with those of other studies, in which women significantly reported higher empathy scores [44, $45,46,47]$. Different explanations have been given for gender differences in empathy scores, such as genetic predispositions and social learning.

When respondents' age was analysed, no significant differences in motivation were observed. The only relevant difference concerned motivations related to job security, which was mainly indicated as a motivation for choosing nursing studies by students who were older than 21 . These results are in accordance with the findings of previous research. In a prior study, male students' self-reported 
motivations for choosing nursing studies were more oriented to job security [40]. Finally, the empathy measure does not appear to be significantly influenced by students' age.

The results confirmed the primary hypothesis that altruistic motivations for choosing nursing studies and students' positive attitude towards the value of empathy in health professionals are significantly associated. Two relevant correlations emerged from the outcome of the PCA in this study. The internal motivation with a more altruistic characterisation is positively correlated with empathy scores. Moreover, when external motivations were considered, a negative correlation was found between these motivations and the JSE-HPS subscale that measures emotional engagement and compassionate care. The obtained results are interesting, as they confirm similar findings that were obtained for other typologies of health professionals. Previous studies investigated the association between empathy and person-oriented motives for enrolling in medical school [30,32]. In one study, empathy was found to be weakly associated with person-centred motivations in recently admitted medical students [30]. Piumatti et al. showed that the internal motivational factors for studying medicine were associated with higher levels of empathy, while external motivational factors were associated with lower levels of empathy [32]. Another study reported that the empathy scores of first-year medical students were positively associated with their intention to pursue people-oriented specialties after graduation [31]. However, these findings do not correspond to those of the present study. Indeed, the targets of these studies were medical students rather than nursing students. Additionally, these studies utilised structured questionnaires and closed questions to measure motivational aspects. To the best of our knowledge, no prior studies have examined this association in the nursing sector.

The present study intends to contribute to a better understanding of the association between students' empathy and their altruistic motivations in engaging in nursing studies. The association between prosocial and altruistic motivations and high scores in an empathy measure is an interesting and new result in nursing studies. First, this analysis can help improve the understanding of the empathy construct, particularly regarding the correlation of specific empathy components with motivational dimensions, especially the willingness to feel useful and to affect the health of others. Moreover, the empathy components related to compassionate care and emotional engagement appear more important if the internal/external structure of the motivational landscape is considered.

This study has some limitations. The use of a qualitative analysis to detect motivations makes it difficult to generalise the results of this study to other subject samples. The use of a structured questionnaire could be more appropriate for generalising the results. The cross-sectional nature of the study prevents the evaluation of causal relationships between the observed variables. The inclusion of students from a single institution may also limit the generalisability of the findings of this study. Moreover, the relationship between empathy and motivation can evolve over time, and only a longitudinal study could provide a better understanding of this evolution. Another aspect to consider is social desirability. Owing to the nature of the construct, the process of measuring empathy is often deeply affected by social desirability bias and acquiescence. Therefore, future research should use a different typology of 
measurements, such as implicit measures of empathy, or measurements of patients' perceptions of health professionals' empathy.

\section{Conclusions}

This study surveyed 77 nursing students enrolled in the first year of a nursing degree course to measure their attitude towards the value of empathy and their motivations for engaging in a degree course in nursing. These two constructs are particularly relevant in health contexts to sustain therapeutic alliances. As a growing amount of empirical scientific research has shown, positive relationships between health professionals and patients are important in the cure and treatment process [1]. This is also supported by biopsychosocial approaches, which recognise that health professionals should consider the patient as a whole $[55,56]$.

A thematic analysis was applied to examine students' motivations, and motivational categories were extracted through a deep and theory-driven analysis of students' answers to an open question. Students' attitudes toward empathy were measured using a robust measurement tool, the Health Professions Students' version of the JSE.

The person-centred analysis of the collected data shows an interesting motivational structure, with some students oriented towards altruistic motivations and others more centred on extrinsic values. This structure appears essentially independent from gender and age. Regarding attitudes toward empathy, the analysis showed higher scores for females, no significant differences with respect to age, and a weak relationship between high empathy scores and altruistic motivations. This correlation is not statistically significant, which is most likely due to the few occurrences of a single category in the student' responses.

A factorial analysis was used to better investigate these relationships, though the prerequisite to carry out a similar analysis is only weakly supported by the data. The decision to use these findings was sustained by other data analyses, such as cluster analysis, by motivational theory, and by the utility of proposing fresh approaches for nursing studies. Factorial analysis associated each student with three motivational scores, after which linear regressions were applied to test the relationship between empathy and motivational profile.

This is the first study that investigated the relationship between empathy and motivations for choosing nursing studies. In summary, high empathy scores were found to be positively associated with altruistic motivational factors. Moreover, a negative correlation was found between external motivational factors and the scores of the Compassionate Care subscale of the JSE. It is interesting to observe that a large proportion of students indicated that they had altruistic motivations for choosing to engage in nursing studies, in accordance with the research literature.

Empathy is considered to be a modifiable dimension, as it is a trainable subject $[13,16,28,57]$. Understanding the level of nursing students' empathy is important for educators, as it allows them to implement training paths to slow the decrease in empathy or to enhance students' relational attitudes 
and skills, which are central aspects for this profession. Moreover, it is crucial to promote specific interventions and activities to support or reinforce the positive motivational aspects that students already possess and that are essential for the nursing profession.

\section{Declarations}

\section{Ethics approval and consent to participate}

According to the local ethical policy, no prior formal authorization approval by the Ethics Committee was necessary. We communicated the study design to the Institutional board of the Degree Nursing Course guaranteeing that ethical standards would be met, and received consent. All participants were given detailed information about the study. Data collection was carried out only after obtaining voluntary informed consent from students.

\section{Consent for publication}

Not applicable.

\section{Availability of data and materials}

The datasets analysed during the current study are available from the corresponding author on reasonable request.

\section{Competing interests}

The authors declare that they have no competing interests.

\section{Funding}

Not applicable.

\section{Authors' contributions}

LM was responsible for the conception and design of the work, and acquisition of data. LM was the primary writer of the article and contributed to the interpretation of data. LM and LS were involved in the process of independently coding of the responses. LS performed statistical analysis of data and participated in interpretation of data and writing of the manuscript. MA reviewed the manuscript and made revisions in important intellectual content. All authors approved the final manuscript.

\section{Acknowledgments}

The authors thank Prof. Mohammadreza Hojat for permission to use the JSE-HPS.

\section{Abbreviations}


JSE: Jefferson Scale of Empathy; JSE-HPS: Jefferson Scale of Empathy - Health Professions Students; EFA: Explorative Factorial Analysis.

\section{References}

1. Kelley JM, Kraft-Todd G, Schapira L, Kossowsky J, Riess H. The influence of the patient-clinician relationship on healthcare outcomes: a systematic review and meta-analysis of randomized controlled trials. PLoS One. 2014;9(4):e94207-e94207.

2. Mead N, Bower P. Patient-centredness: a conceptual framework and review of the empirical literature. Soc Sci Med. 2000;51(7):1087-110.

3. Bartlett EE, Grayson M, Barker R, Levine DM, Golden A, Libber S. The effects of physician communications skills on patient satisfaction; Recall, and adherence. J Chronic Dis.. 1984;37(9):755-64.

4. Zachariae R, Pedersen CG, Jensen AB, Ehrnrooth E, Rossen PB, von der Maase H. Association of perceived physician communication style with patient satisfaction, distress, cancer-related selfefficacy, and perceived control over the disease. Br J Cancer. 2003;88(5):658-65.

5. Kim SS, Kaplowitz S, Johnston MV. The Effects of Physician Empathy on Patient Satisfaction and Compliance. Eval Health Prof. 2004;27(3):237-51.

6. Hojat M, Louis DZ, Markham FW, Wender R, Rabinowitz C, Gonnella JS. Physicians' Empathy and Clinical Outcomes for Diabetic Patients. Acad Med. 2011;86(3).

7. Parkin T, de Looy A, Farrand P. Greater professional empathy leads to higher agreement about decisions made in the consultation. Patient Educ Couns. 2014;96(2):144-50.

8. Veloski J, Hojat M. Measuring specific elements of professionalism: empathy, teamwork, and lifelong learning In: Stern DT, editor, ed. Measuring Medical Professionalism. Oxford, UK: Oxford University Press; 2006:117-145.

9. Crandall SJ, Marion GS. Commentary: Identifying Attitudes Towards Empathy: An Essential Feature of Professionalism. Acad Med. 2009;84(9).

10. Rogers CR. Client-centered therapy; its current practice, implications, and theory. Boston, MA: Houghton Mifflin; 1951.

11. Olson JK. Relationships between nurse-expressed empathy patient-perceived empathy and patient distress. J Nurs Scholarsh. 1995; 27(4), 317-322.

12. Hojat M. Empathy in patient care: Antecedents, development, measurement, and outcomes. New York, NY: Springer 2007.

13. Brunero S, Lamont S, Coates M. A review of empathy education in nursing. Nurs Inq. 2010;17(1):6574.

14. Berkhof M, van Rijssen HJ, Schellart AJM, Anema JR, van der Beek AJ. Effective training strategies for teaching communication skills to physicians: An overview of systematic reviews. Patient Educ Couns 2011;84(2):152-62. 
15. Williams J, Stickley T. Empathy and nurse education. Nurse Educ Today. 2010;30(8):752-5.

16. Hojat M, Axelrod D, Spandorfer J, Mangione S. Enhancing and sustaining empathy in medical students. Med Teach. 2013;35(12):996-1001.

17. Pedersen R. Empirical research on empathy in medicine-A critical review. Patient Educ Couns. 2009;76(3):307-22.

18. Hemmerdinger JM, Stoddart SD, Lilford RJ. A systematic review of tests of empathy in medicine. BMC Med Educ. 2007;7(1):24.

19. Yu J, Kirk M. Measurement of empathy in nursing research: systematic review. J Adv Nurs. 2008;64(5):440-54.

20. Yu J, Kirk M. Evaluation of empathy measurement tools in nursing: systematic review. J Adv Nurs. 2009;65(9):1790-806.

21. Hojat M, Mangione S, Nasca TJ, Rattner S, Erdmann JB, Gonnella JS, et al. An empirical study of decline in empathy in medical school. Med Educ. 2004;38(9):934-41.

22. Neumann M, Edelhäuser F, Tauschel D, Fischer MR, Wirtz M, Woopen $C$, et al. Empathy Decline and Its Reasons: A Systematic Review of Studies With Medical Students and Residents. Acad Med. 2011;86(8).

23. Ward J, Cody J, Schaal M, Hojat M. The Empathy Enigma: An Empirical Study of Decline in Empathy Among Undergraduate Nursing Students. J Prof Nurs. 2012;28(1):34-40.

24. Colliver JA, Conlee MJ, Verhulst SJ, Dorsey JK. Reports of the Decline of Empathy During Medical Education Are Greatly Exaggerated: A Reexamination of the Research. Acad Med. 2010;85(4).

25. Quince TA, Parker RA, Wood DF, Benson JA. Stability of empathy among undergraduate medical students: a longitudinal study at one UK medical school. BMC Med Educ. 2011;11:90-90.

26. Quince TA, Kinnersley P, Hales J, da Silva A, Moriarty H, Thiemann P, et al. Empathy among undergraduate medical students: A multi-centre cross-sectional comparison of students beginning and approaching the end of their course. BMC Med Educ. 2016;16(1):92.

27. Batt-Rawden SA, Chisolm MS, Anton B, Flickinger TE. Teaching Empathy to Medical Students: An Updated, Systematic Review. Acad Med. 2013;88(8).

28. Hojat M, Mangione S, Nasca TJ, Cohen MJM, Gonnella JS, Erdmann JB, et al. The Jefferson Scale of Physician Empathy: Development and Preliminary Psychometric Data. Educ Psychol Meas. 2001;61(2):349-65.

29. Jeffreys MR. Nursing Student Retention: Understanding the Process and Making a Difference. New York: Springer; 2012.

30. Gonçalves-Pereira M, Loureiro J, Trancas B, Papoila A, \& Caldas-de-Almeida JM. Empathy as Related to Motivations for Medicine in a Sample of First-Year Medical Students. Psychological Reports, 2013;112(1),73-88. https://doi.org/10.2466/17.13.PR0.112.1.73-88.

31. Hojat M, Zuckerman M, Magee M, Mangione S, Nasca T, Vergare M, et al. Empathy in medical students as related to specialty interest, personality, and perceptions of mother and father. Pers 
Individ Dif. 2005;39(7):1205-15.

32. Piumatti G, Abbiati M, Baroffio A, Gerbase MW. Associations between motivational factors for studying medicine, learning approaches and empathy among medical school candidates. Adv Health Sci Educ Theory Pract. 2019;24(2):287-300. https://doi.org/10.1007/s10459-018-9866-6.

33. Calabrese LH, Bianco JA, Mann D, Massello D, Hojat M. Correlates and Changes in Empathy and Attitudes Toward Interprofessional Collaboration in Osteopathic Medical Students. J Am Osteopath Assoc. 2013;113(12):898-907. https://doi.org/10.7556/jaoa.2013.068.

34. Larsen PD, McGill JS, Palmer SJ. Factors influencing career decisions: perspectives of nursing students in three types of programs. J Nurs Educ. 2003; 42(4):168-73.

35. Zysberg L, Berry DM. Gender and students' vocational choices in entering the field of nursing. Nurs Outlook. 2005; 53(4):193-8. https://doi.org/10.1016/j.outlook.2005.05.001.

36. Miers ME, Rickaby CE, Pollard KC. Career choices in health care: Is nursing a special case? a content analysis of survey data. Int J Nurs Stud. 2007; 44(7):1196-209. https://doi.org/10.1016/j.ijnurstu.2006.04.010.

37. Mooney M, Glacken M, O’Brien F. Choosing nursing as a career: A qualitative study. Nurse Educ Today. 2008; 28(7):385-92. https://doi.org/10.1016/j.nedt.2007.07.006.

38. Jirwe M, Rudman A. Why choose a career in nursing?. J Adv Nurs. 2012;68(7):1615-23. https://doi.org/10.1111/j.1365-2648.2012.05991.x.

39. Wilkes $L$, Cowin $L$, Johnson $M$. The reasons students choose to undertake a nursing degree. Collegian. 2015; 22(3):259-65. https://doi.org/10.1016/j.colegn.2014.01.003.

40. Messineo L, Allegra M, Seta L. Self-reported motivation for choosing nursing studies: a selfdetermination theory perspective. BMC Med Educ. 2019;19(1):192.

41. Dante A, Graceffa G, Del Bello M, Rizzi L, landerca B, Battistella N, Bulfone T, Grando R, Zuliani S, Casetta A, Palese A. Factors influencing the choice of a nursing or a non-nursing degree: a multicenter, cross-sectional study. Nurs Health Sci. 2014;16(4):498-505. doi: 10.1111/nhs.12126.

42. Dante A, Rizzi L, landerca B, Palese A. Why do university students not choose a nursing degree at matriculation? An Italian cross-sectional study. Int Nurs Rev. 2013;60(1):129-35. doi: 10.1111/j.14667657.2012.01037.x.

43. Eisenberg N, Miller PA. The relation of empathy to prosocial and related behaviors. Psychol Bull. 1987;101(1):91-119.

44. Hojat M, Gonnella JS, Mangione S, Nasca TJ, Veloski JJ, Erdmann JB, et al. Empathy in medical students as related to academic performance, clinical competence and gender. Med Educ. 2002;36(6):522-7.

45. Berg K, Majdan JF, Berg D, Veloski J, Hojat M. Medical Students' Self-Reported Empathy and Simulated Patients' Assessments of Student Empathy: An Analysis by Gender and Ethnicity. Acad Med. 2011;86(8). 
46. Fjortoft N, Van Winkle LJ, Hojat M. Measuring empathy in pharmacy students. Am J Pharm Educ. 2011;75(6):109-109.

47. Wen D, Ma X, Li H, Liu Z, Xian B, \& Liu Y. Empathy in Chinese medical students: psychometric characteristics and differences by gender and year of medical education. BMC Med Educ. 2013;13:130. doi:10.1186/1472-6920-13-130.

48. Montanari P, Petrucci C, Russo S, Murray I, Dimonte V, Lancia L. Psychometric properties of the Jefferson Scale of Empathy-Health Professional Student's version: An Italian validation study with nursing students. Nurs Health Sci. 2015;17(4):483-491. https://doi.org/10.1111/nhs.12221.

49. Braun V, \& Clarke V. Using thematic analysis in psychology. Qual Res Psychol. 2006:3,77-101. https://doi.org/10.1191/ 1478088706qp063oa.

50. Nowell LS, Norris JM, White DE, \& Moules NJ. Thematic Analysis: Striving to Meet the Trustworthiness Criteria. Int J Qual Methods. 2017;16,1-13.

51. Cohen L, Manion L, \& Morrison K. Research Methods in Education, Routledge: New York; 2007.

52. Lincoln YS, \& Guba E. Naturalistic Inquiry. Beverly Hills, CA: Sage; 1985.

53. Eisenhart MA, \& Howe KR. Validity in educational research. In LeCompte MD, Millroy WL \& Preissle J (eds). The Handbook of Qualitative Studies in Education. New York: Academic Press; 1992.

54. DeSantis L, Ugarriza DN. The Concept of Theme as Used in Qualitative Nursing Research. Western Journal of Nursing Research. 2000;22(3):351-372. doi:10.1177/019394590002200308

55. Engel G. The need for a new medical model: a challenge for biomedicine. Science. 1977;196:129136.

56. Frankel, R.M., Quill, T.E., McDaniel, S.H. (Eds.). The Biopsychosocial Approach: Past, Present, Future. University of Rochester Press, Rochester, NY, 2003.

57. Gholamzadeh S, Khastavaneh M, Khademian Z, Ghadakpour S. The effects of empathy skills training on nursing students' empathy and attitudes toward elderly people. BMC Med Educ. 2018;18:198. https://doi.org/10.1186/s12909-018-1297-9.

\section{Tables}

Table 1. Inductively inferred categories 


\begin{tabular}{|c|c|c|}
\hline Theme & Brief description & Illustrative quotes \\
\hline HEL & $\begin{array}{l}\text { Willingness to feel useful and to } \\
\text { affect the health of others. }\end{array}$ & $\begin{array}{l}\text { 'I want to be of help to others; I want to contribute to trying to improve } \\
\text { the lives of others.' } \\
\text { 'I chose this degree programme to make myself useful for others' }\end{array}$ \\
\hline HUM & $\begin{array}{l}\text { The desire to enter in contact } \\
\text { with other people. }\end{array}$ & $\begin{array}{l}\text { 'I chose the degree course in nursing ... because I like being in contact } \\
\text { with people.' } \\
\text { 'I love being in contact with people.' }\end{array}$ \\
\hline FAM & $\begin{array}{l}\text { Significant others, such as } \\
\text { family members, have } \\
\text { significant influence on the } \\
\text { students' career decision. }\end{array}$ & $\begin{array}{l}\text { 'Also, because there is a nurse in my family, that is, my grandmother, } \\
\text { who was always an example for me.' } \\
\text { 'When my brother, also a nurse, told me about his experiences in the } \\
\text { ward, I was fascinated.' }\end{array}$ \\
\hline TOP & $\begin{array}{l}\text { A personal interest in health- } \\
\text { related scientific topics. }\end{array}$ & $\begin{array}{l}\text { 'I chose this course of study because I like the subjects in this degree } \\
\text { course.' } \\
\text { 'First of all, because I love the subjects that are studied in the nursing } \\
\text { degree course' }\end{array}$ \\
\hline JOB & $\begin{array}{l}\text { The possibility of a secure } \\
\text { employment and job stability. }\end{array}$ & $\begin{array}{l}\text { 'I chose the undergraduate degree in nursing... to have greater job } \\
\text { opportunities after finishing my studies.' } \\
\text { 'Another reason ... is because I hope to find work faster.' }\end{array}$ \\
\hline EXP & $\begin{array}{l}\text { Healthcare-related experience, } \\
\text { such as voluntary work in } \\
\text { healthcare settings or a family } \\
\text { member's hospitalisation. }\end{array}$ & $\begin{array}{l}\text { 'I have chosen to undertake these studies and subsequently enrol in the } \\
\text { degree course in nursing because I feel alive only when I help and offer } \\
\text { support to others and I received confirmation following the illness of a } \\
\text { person to whom I was very attached.' } \\
\text { 'I found myself at home in close contact with a grandfather to look after, } \\
\text { I was his personal nurse, and this made me a happy person.' }\end{array}$ \\
\hline Other & $\begin{array}{l}\text { Not being able to get into other } \\
\text { chosen study programme, etc. }\end{array}$ & $\begin{array}{l}\text { '...I tried (to get into) the medicine degree course, but I wasn't } \\
\text { admitted.' }\end{array}$ \\
\hline
\end{tabular}


Table 2. Absolute and relative frequencies of motivation categories; relative frequencies of categories with respect to students' gender and ages

\begin{tabular}{cccccccc}
\hline & $\mathrm{n}$ & Tot $(\%)$ & Females (\%) & Males (\%) & Young (\%) & $\begin{array}{r}\text { Mid (\%) } \\
\text { Old } \\
(\%)\end{array}$ \\
\hline EXP & 14 & 18.18 & 25.00 & 7.41 & 18.75 & 22.22 & 11.11 \\
HUM & 19 & 24.68 & 27.08 & 22.22 & 25.00 & 29.63 & 16.67 \\
\hline HEL & 57 & 74.03 & 83.33 & 62.96 & 75.00 & 81.48 & 61.11 \\
\hline FAM & 5 & 6.49 & 4.17 & 11.11 & 3.12 & 7.41 & 11.11 \\
\hline JOB & 22 & 28.57 & 18.75 & 48.15 & 28.12 & 22.22 & 38.89 \\
\hline TOP & 17 & 22.08 & 16.67 & 33.33 & 18.75 & 25.93 & 22.22 \\
\hline
\end{tabular}

Young: students with age $£ 19$ years; Mid: students with age $>19$ and $£ 21$ years; Old: students with age $>21$ years. EXP: Healthcare-related personal experiences; HUM: Human contact; HEL: Willingness to care for people; FAM: Family tradition; JOB: Job opportunities; TOP: Personal interest in scientific topics.

Table 3. Component matrix for motivational categories

\begin{tabular}{cccc}
\hline & RC1 & RC2 & RC3 \\
\hline EXP & -0.25 & -0.54 & 0.55 \\
HUM & 0.07 & 0.14 & 0.91 \\
\hline HEL & 0.63 & -0.42 & 0.07 \\
\hline FAM & $\mathbf{0 . 6 8}$ & 0.11 & -0.10 \\
\hline JOB & -0.08 & 0.88 & 0.14 \\
\hline TOP & -0.63 & 0.01 & -0.03 \\
\hline
\end{tabular}

The highest absolute load for each motivational item is in bold.

RCs are the three Rotated Components.

Extraction Method: Principal Component Analysis.

Rotation Method: Varimax with Kaiser Normalisation

Table 4. Descriptive statistics for JSE-HPS ( $\mathrm{N}=77$ first-year nursing students)

\begin{tabular}{lllll}
\hline Statistics & Total & Perspective taking & Compassionate care & Standing in patient's shoes \\
\hline Mean & 111.88 & 57.6 & 44.69 & 9.60 \\
Standard Deviation & 11.90 & 7.35 & 5.39 & 2.66 \\
\hline $25^{\text {th }}$ percentile & 104 & 53 & 41 & 8 \\
\hline $50^{\text {th }}$ percentile (median) & 113 & 60 & 45 & 9 \\
\hline $75^{\text {th }}$ percentile & 122 & 62 & 49 & 11 \\
\hline Possible Range & $20-140$ & $10-70$ & $8-56$ & $2-14$ \\
\hline Actual Range & $75-132$ & $36-70$ & $28-55$ & $4-14$ \\
\hline Cronbach's alpha & 0.79 & 0.65 & 0.58 & 0.56 \\
\hline
\end{tabular}


Table 5. Comparisons of the total JSE-HPS scores for first-year nursing students with respect to different groups: gender, age, and motivational categories

\begin{tabular}{|c|c|c|c|c|c|}
\hline Groups & $\mathrm{n}$ & $\mathrm{M}$ & $\mathrm{SD}$ & $\mathrm{U}_{\text {test }}{ }^{(1)}$ & p-value \\
\hline \multicolumn{6}{|l|}{ Sex } \\
\hline Male students & 29 & 106.90 & 12.97 & 942.5 & $.005^{* *}$ \\
\hline Female students & 48 & 114.90 & 10.20 & & \\
\hline All students & 77 & 111.88 & 11.90 & & \\
\hline \multicolumn{6}{|l|}{ Age class } \\
\hline Young (£ 19 years) & 32 & 112.75 & 11.86 & 762 & .332 \\
\hline Mid ( $>19$ and $£ 21$ years) & 27 & 110.41 & 11.92 & 596 & .199 \\
\hline Old (> 21 years) & 18 & 112.56 & 12.39 & 568 & .328 \\
\hline \multicolumn{6}{|l|}{ Nursing motivation } \\
\hline Healthcare-related personal experiences (EXP) & 14 & 112.86 & 15.38 & 499 & .222 \\
\hline Human contact (HUM) & 19 & 109.84 & 13.48 & 505 & .293 \\
\hline The willingness to care for people (HEL) & 57 & 112.95 & 9.80 & 614 & .302 \\
\hline Family tradition (FAM) & 4 & 113.00 & 11.25 & 186 & .451 \\
\hline Job opportunities (JOB) & 22 & 109.59 & 12.35 & 515.5 & .156 \\
\hline Personal interest (TOP) & 17 & 105.35 & 15.32 & 348.5 & $.024 *$ \\
\hline
\end{tabular}

(1) For the group comparison, the Mann-Whitney U non-parametric test was used, dividing the sample into two independent groups according to their membership status. The symbols $\left(^{*}\right)$ and $(* *)$ indicate levels of significance greater than $95 \%$ and $99 \%$, respectively.

Table 6. Two regression models between the RC1 and RC2 dimensions for students' motivation and JSE-HPS scores

\begin{tabular}{llllll}
\hline \multicolumn{7}{c}{ Estimate } & $S E$ & $t$ value & $\operatorname{Pr}(>|t|)$ & \\
\hline Model: $R C 1$ & $\sim$ JSE_TOT & & & & \\
\hline (intercept) & -.1 .888 & 1.070 & -1.765 & 0.0816 & $\cdot$ \\
JSE_TOT & 0.017 & 0.009 & 1.777 & 0.080 & $\cdot$ \\
\hline Model: RC2 & $\sim J S E \_C C$ & & & & \\
\hline (intercept) & 1.865 & 0.939 & 1.986 & 0.051 & $\cdot$ \\
JSE_CC & .0 .042 & 0.021 & .2 .000 & 0.049 & $*$ \\
\hline
\end{tabular}

JSE_TOT: JSE-HPS total score.

JSE_CC: scores in the JSE-HPS subscale 'Compassionate Care'.

RC1 and RC2 the first two Rotated Component obtained in the PCA (Table 3)

Figures 


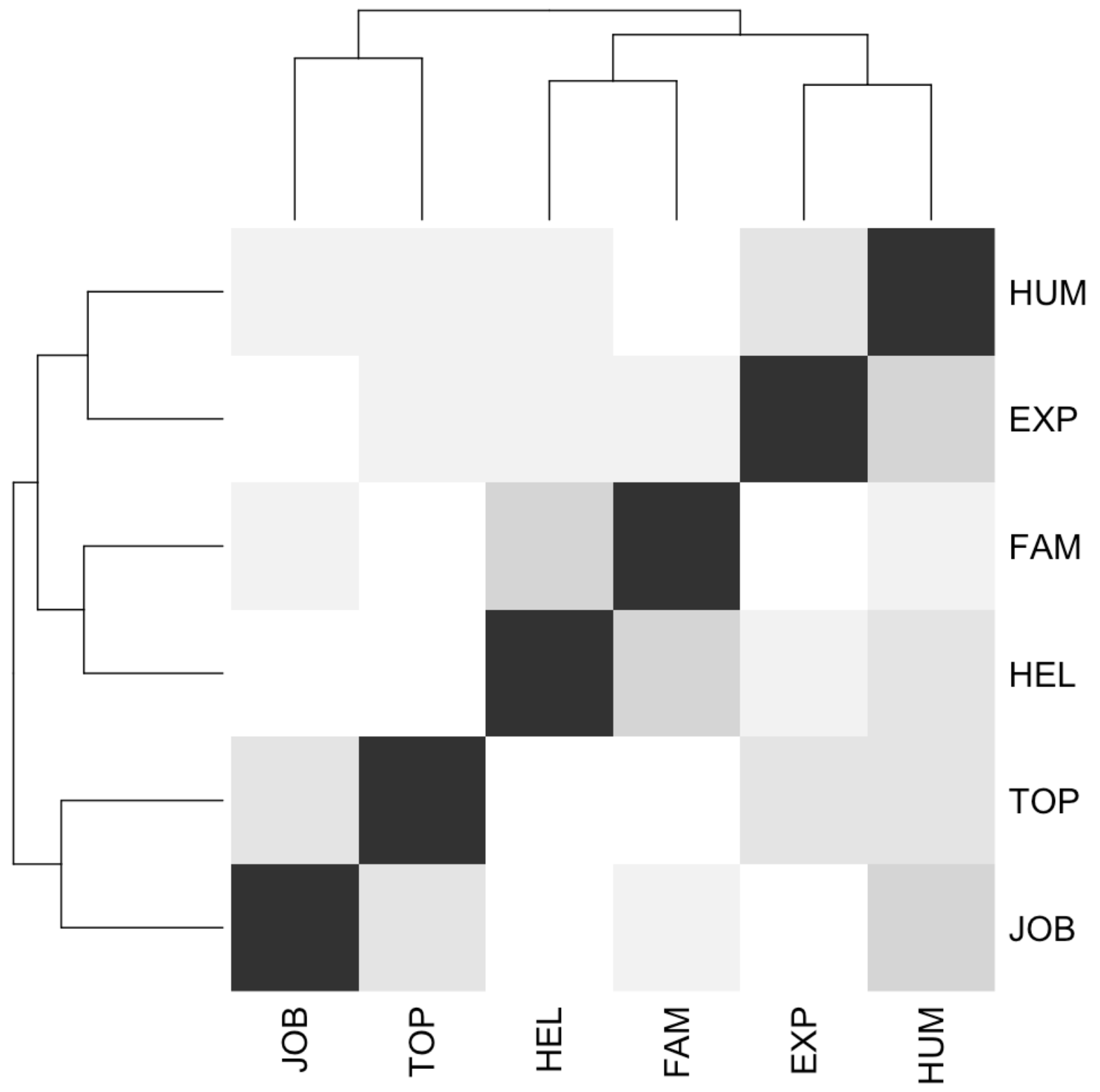

Figure 1

Associations among categories using the correlation matrix The intensity of the colour grey indicates a stronger association; clusters are highlighted on the left and superior margins 